\title{
Further Development of Atmosphere Pressure Field Research in the Arctic Region of Russia
}

\author{
Natalia P. Tuchkova ${ }^{1}$, Konstantin P. Belyaev ${ }^{2}$, Gury M. Mikhaylov ${ }^{3}$, Alexey N. Salnikov ${ }^{4}$ \\ 1,2,3,4 Dorodnicyn Computing Center FRC CSC of RAS, Vavilov str., 40, Moscow, 119333, Russia \\ ${ }^{2}$ Shirshov Institute of Oceanology of RAS, Nahimovskiy pr., 36, Moscow, 117218, Russia \\ ${ }^{4}$ Lomonosov Moscow State University, GSP-1, Leninskie Gory, Moscow, 11999, Russia
}

\begin{abstract}
The results of studies of atmospheric pressure in the Arctic region of Russia for the period from 1948 to 2008 presented. The analysis of the climatic seasonal variation of the atmospheric pressure fields has been carried out. As the main research method, the probabilistic and statistical analysis of the time series of the pressure field during 60 years at fixed points in the region of the Arctic zone of Russia was used. In total, about 90,000 daily (with a six-hour interval) pressure values were studied. Based on these data, the climatic seasonal variability was constructed as an averaging of the values of a given time series at each point in space and for a fixed date. The characteristics of the seasonal cycle, its amplitude and phase have been analyzed. Those characteristics were studied and their geophysical interpretation was carried out. In particular, the minimum and maximum values of the series were determined for the entire region and the time series of these characteristics were constructed. It is shown that the deviation is asymmetrical in nature; this is an unobvious result of research. For the maximum and minimum, the best approximations were proposed, and these approximations were tested by known methods of statistical analysis, including maximum likelihood, least squares and goodness of fit methods (tests), in particular, the $\chi^{2}$ test. The performed study has applications both purely physical (allows to explain the nature, genesis and distribution of large-scale atmospheric formations in a climatic year) and prognostic (allows to understand and track trends in climate, as well as to quantitatively estimate the scale and variability of large-scale atmospheric processes). Numerical calculations were performed on the Lomonosov-2 supercomputer of the Moscow State University named after M.V. Lomonosov.
\end{abstract}

\section{Keywords}

Time series analysis, climatic seasonal variability, maximum and minimum pressure values within a climatic annual cycle

\section{Introduction}

The work utilized the methods of time series analysis, in particular, the separation of the time series into periodic and non-periodic components. Such methods are successfully used in the analysis of the financial market [1] and long-term variability of geophysical characteristics, such as the temperature of air or water [2], as well as in more complex models and schemes [3]. In geophysical schemes and models, the concept of climatic seasonal variability is frequently used, when the average values of the entire time series are plotted for each date of the year and at each fixed point in space. For example, all the values on January 1 at a specific point in space for the entire observation period are averaged, and as a result, the average value of the series for January 1 is plotted, which is considered as a climatic value. This procedure is carried out for each day within the year. Such a way, the climatic seasonal

SSI-2021: Scientific Services \& Internet, September 20-23, 2021, Moscow (online)

EMAIL: natalia_tuchkova@mail.ru (N.P. Tuchkova); kosbel55@gmail.com (K.P. Belyaev); gmickail@ccas.ru (G.M. Mikhaylov); salnikov@angel.cs.msu.ru (A.N. Salnikov)

ORCID: 0000-0001-6518-5817 (N.P. Tuchkova), 0000-0003-2111-2709 (K.P. Belyaev), 0000-0002-4535-7180 (G.M. Mikhaylov), 0000-0001-8669-9905 (A.N. Salnikov)

(c) (i) 2021 Copyright for this paper by its authors.

Use permitted under Creative Commons License Attribution 4.0 International (CC BY 4.0)

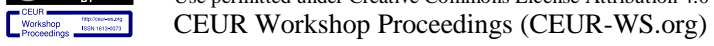


variability of a specific physical characteristic is built. This method is described in detail, for example, in [4]. Further in the studies, it is possible to analyze in more detail the obtained series of observations, for example, to select the maximum and (or) minimum values of this physical characteristic over a given area and to study the variability of only these maximum or minimum. Note the importance of these characteristics, since, for example, in the field of atmospheric pressure. These extrema are associated with such physical processes as cyclones and anti-cyclones, their localization and variability.

Plenty of modern works have been devoted to the study of the Arctic region, since the climate of this region has been especially subject to changes due to global warming in recent decades, which has led to a significant decrease in snow and ice cover [5-8]. For example, paper [8] presents the results of the analysis of the pressure fields of the Arctic region in the "early instrumental" period 1801-1920. These data refer to the time when the collection of meteorological data from the network of regular stations has started. The data array of observations [9] over 20 years is insufficient to assess the climatic seasonal variation, but their analysis allowed the authors to get an idea of the state of pressure in the Arctic and find out that, in general, it was lower than the current one.

Many works are also devoted to the study of anomalies, deviations from the corresponding mean $[10,11]$. Anomaly indices [12] made it possible to combine series with similar characteristics. It was found that below zero anomalies of the mean annual air temperature and positive anomalies in the total ice extent of the seas of the Siberian shelf prevailed from the mid-1950s to the end of the 1980s and were accompanied by weaker high-latitude zonal transport in the troposphere, strengthening of the Arctic High, and other features [13].

This work continues the studies published earlier in $[14,15]$. Just as in those ones, here the atmospheric pressure field was used in the area bounded by the coordinates of $62^{\circ} \mathrm{N}-80^{\circ} \mathrm{N}$ and $15^{\circ} \mathrm{E}-60^{\circ} \mathrm{E}$. On the one hand, this area is wide enough to ignore the local features of atmospheric processes, on the other, it is sufficiently uniform, since the sizes of large atmospheric formations are comparable to the dimensions of the entire area. By time, pressure data were recorded from January 1, 1948 to December 31, 2008, daily in a one-degree grid. These data were obtained at the Hydro-meteorological Center of Russia and were used earlier in several works, for example, [16].

This article presents the results of a probabilistic analysis of atmospheric pressure fields, carried out on the basis of separating of the entire series into periodic and non-periodic components. Such an analysis was carried out for the maximum and minimum values of the pressure fields in the region and within the climatic year. It is shown that the studied processes can be represented as a sum, where one term characterizes a regular periodic signal, and the other is a random process independent of the first one. The characteristics of this random process can be determined from the obtained sample. In this case, both the periodic signal and the characteristics of the random process for the maximum and minimum pressure is different, have their own fundamental features and require additional study.

For the considered atmospheric pressure fields in the region the maxima and minima values differ markedly. If the minima in space change from $980 \mathrm{hPa}$ to $995 \mathrm{hPa}$, then the maxima change from $1010 \mathrm{hPa}$ to $1025 \mathrm{hPa}$, and these values "migrate" within the region during the year. This is due to the behavior of cyclones and anticyclones, their movement, deepening and restructuring. In the Arctic region of Russia, there are noticeably more cyclones during the climatic year than anticyclones. Therefore, the distributions of their characteristics are different. Note that the size of the cyclonic atmospheric formation, which mainly forms the pressure field, is comparable to the size of the entire area under consideration. In other words, we are dealing with one, maximum, two cyclones and anticyclones at the same time.

The following research was done in the work:

- built a climatic seasonal process for the field of atmospheric pressure in the Arctic region of Russia, described its features for maximum and minimum values in the area;

- time dependence of these characteristics were built, their analysis was carried out;

- the division of these processes into periodic and aperiodic components was carried out, the amplitudes and phases of the periodic components were estimated;

- for the aperiodic components, the approximations of the observed values that are optimal in terms of the minimum variances are selected, their agreement with the approximating distributions is shown. 


\section{Observational data for pressure fields}

Consider the field of atmospheric pressure in the area bounded by coordinates $62^{\circ}-80^{\circ} \mathrm{N}$ and $15^{\circ}-$ $60^{\circ} \mathrm{E}$, that is, the European part of the Arctic zone of Russia, including the Baltic coast, the waters of the White and Barents Seas to the Kara Sea and the Yamal Peninsula. This is a sufficiently wide area to neglect the local features of atmospheric processes, and also fairly uniform, since the sizes of large atmospheric formations are comparable to the sizes of this area. Pressure observational data were recorded in the period from 01.01.1948 to 31.12.2008 every day with an interval of 6 hours in a one-degree grid.

For clarity, we will present the pressure fields themselves, which are typical for this region. In Figure 1 shows the average pressure field for each point of the European part of the Arctic zone of the Russian Federation for 60 years from 1948 to 2008. It can be seen that the field is a rather smooth surface in space, although if the values themselves are presented in the form of a curve (Figure 2), then jumps and anomalies within the annual seasonal variation become noticeable.

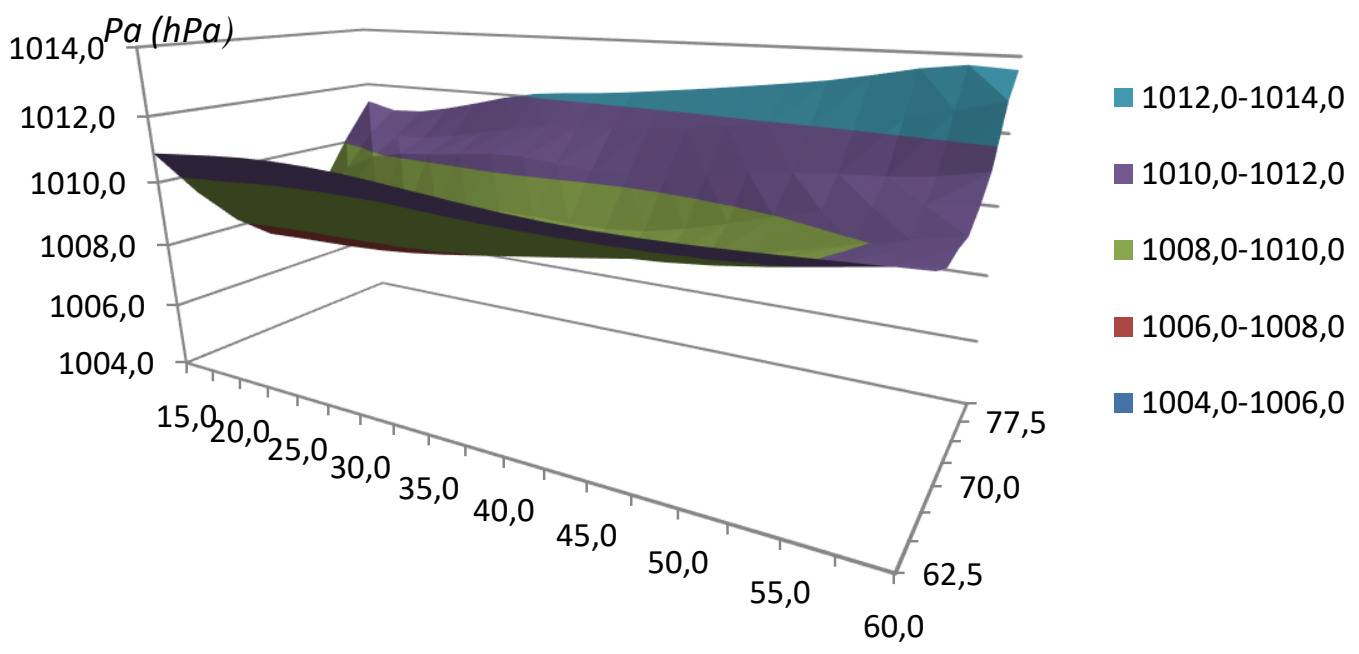

Figure 1: Average values field of pressure over 60 years for each point of the area bounded by coordinates $62^{\circ}-80^{\circ} \mathrm{N}$ and $15^{\circ}-60^{\circ} \mathrm{E}$

Figure 2 shows the curve of changes in the average values for the entire time period of observations for each day. One can see that there are no visible lows, but there are periods of the largest jumps in values, for example, in 1958 and 1968-1988. Since 1975, according to the Hydro-meteorological Center of the Russian Federation, there has been a trend towards an increase in temperature jumps, which is shown in [17] on the picture of anomalies in the mean annual air temperature in the Arctic region.

The difference in the anomalies of mean values for the period 1948-2008 over the European part of the Arctic zone of Russia is $8.04 \mathrm{hPa}$, and for the period 1882-1990 over the entire Arctic region, regarding to studies $[9$, Table VII $]-1.4 \mathrm{hPa}$. This comparison gives an indication of the change in the trend of the observed values. 


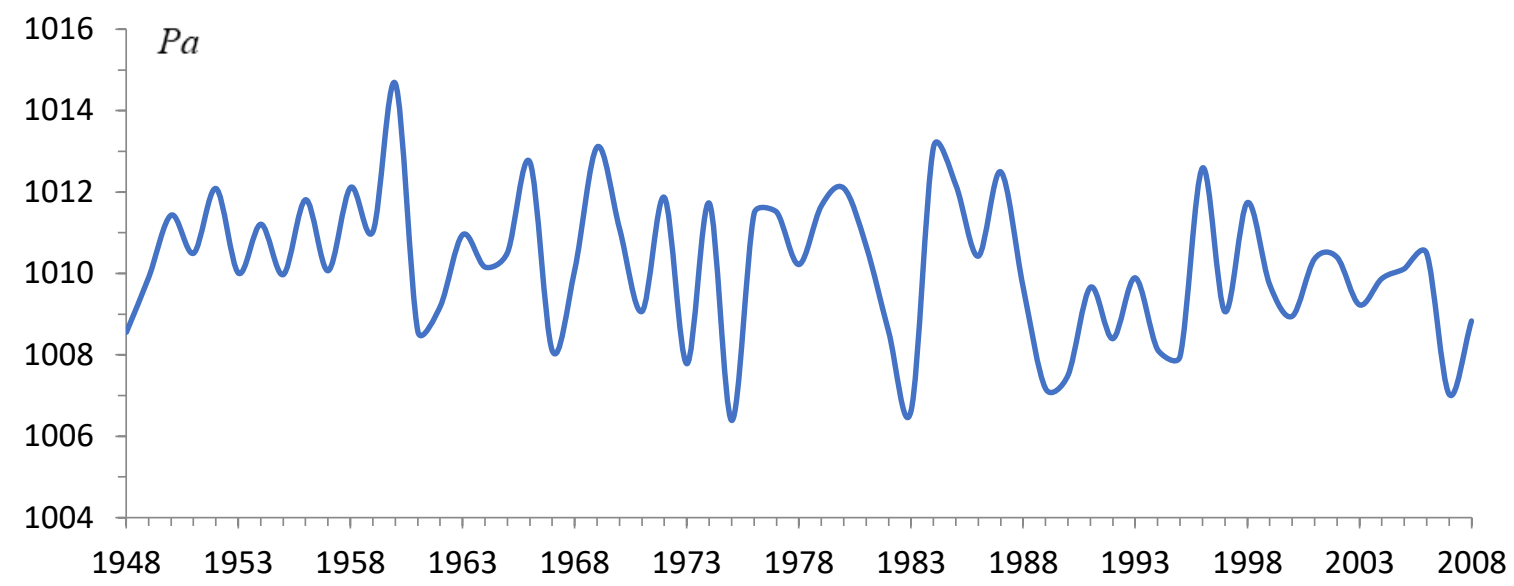

Figure 2: The curve of average pressure values for each day for 60 years from 01.01 .1948 to 12.31.2008 in the Arctic zone of the Russian Federation

\section{Results of analysis of field pressure}

In the considered fields, areas of minimum and maximum pressure for each day were identified and graphs of their behavior were plotted for annual climate cycle values.

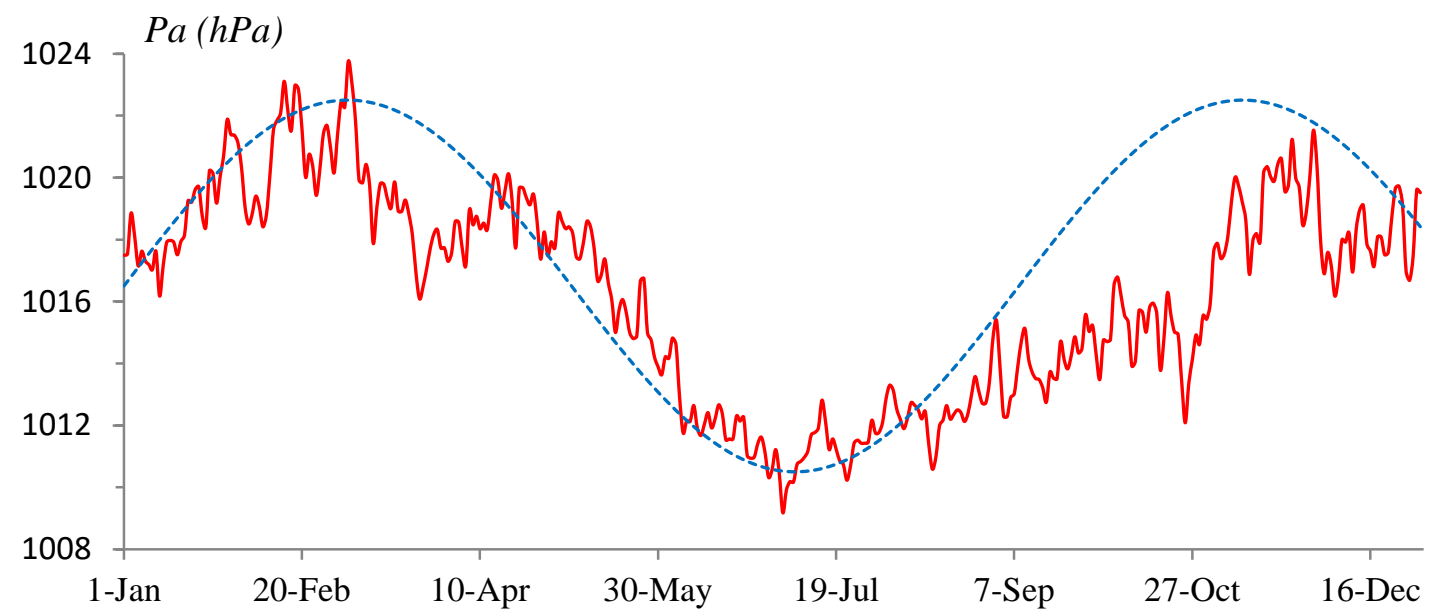

Figure 3: Behavior of the average annual pressure maximum - red line; approximation - blue dotted line

Figure 3 shows the graphs of the average maximum of the climatic annual cycle for the period under consideration and the approximating function. The behavior of the average annual pressure maximum $\mathrm{Pa}(\mathrm{yr})$ over the entire region for the period from 1948 to 2008 and over the space of $62.5^{\circ}-80^{\circ} \mathrm{N}$ and $15^{\circ}-60^{\circ} \mathrm{E}$ is shown versus to the trigonometric function averaged over the observational data set. In Figure 3 it is very clear that the behavior of the maximum can be represented as a sum of a trigonometric function and a random remain. 


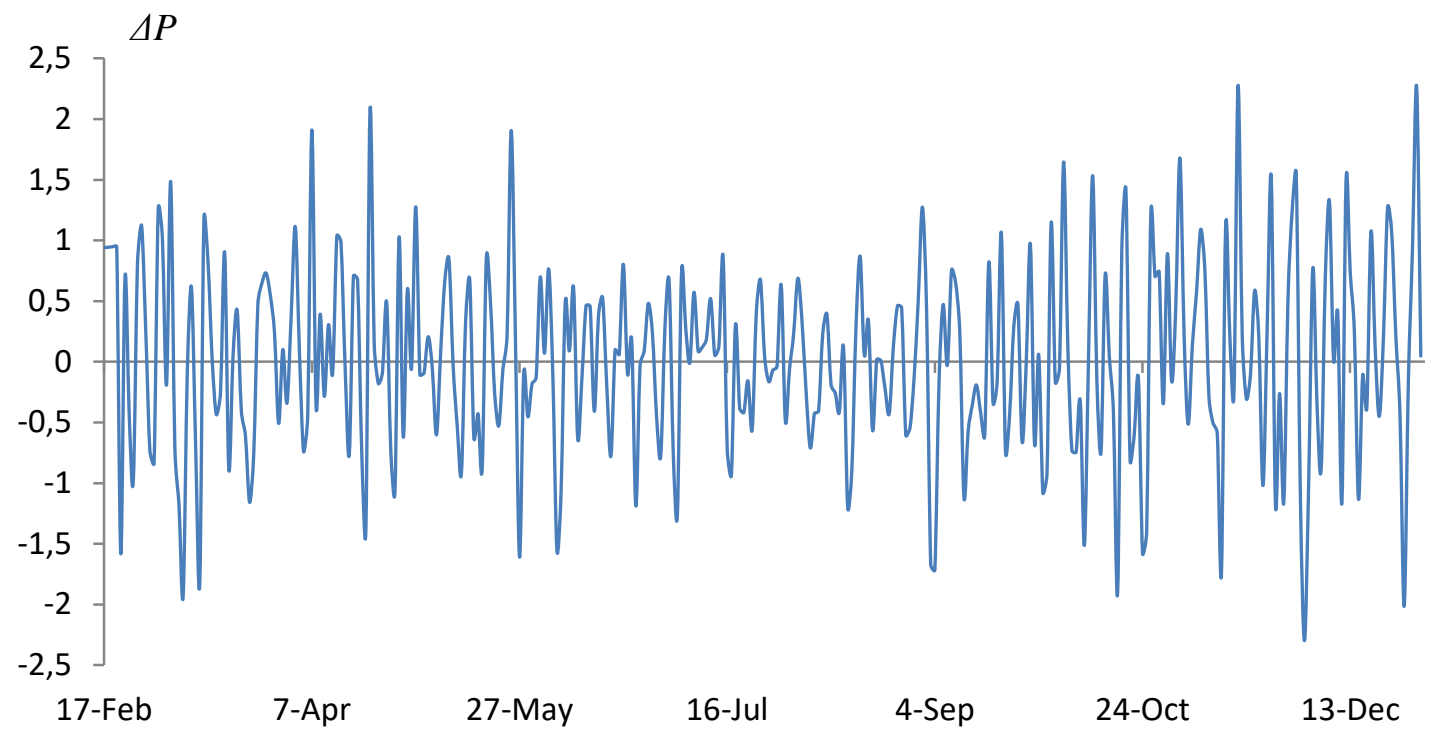

Figure 4: Difference between the observed and approximating curves for the mean annual maximum pressur

The least squares method can be used to find the parameters of this trigonometric function, which turns out to be equal, where $\mathrm{A}=1016.5(\mathrm{hPa}), \mathrm{B}=6(\mathrm{hPa}), \omega=0.01$ (year $\left.^{-1}\right)$. After subtracting its approximation from the "red line", the curve $(\triangle \mathrm{Pa})$ is shown in Figure 4 (the initial of coordinates has been moved for better presentation).

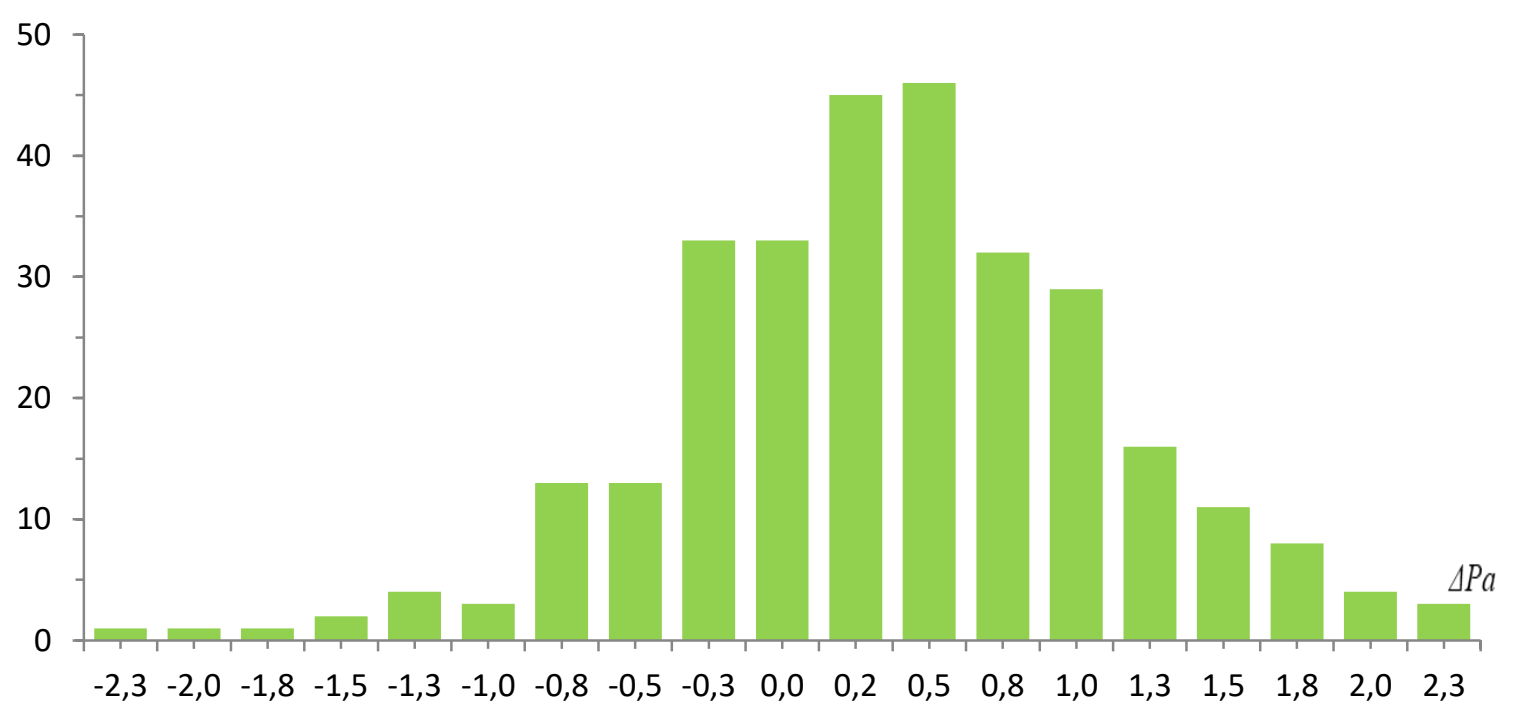

Figure 5: Hystogramm of maxima for $\triangle P a$ annual seasonal cycle

This histogram quite well, with the required degree of probability with respect to the $\chi^{2}$ criterion, agrees with two distributions: Gaussian (Pd1) and Maxwell (Pd2), which is shown in Figure $6(a, b)$. 

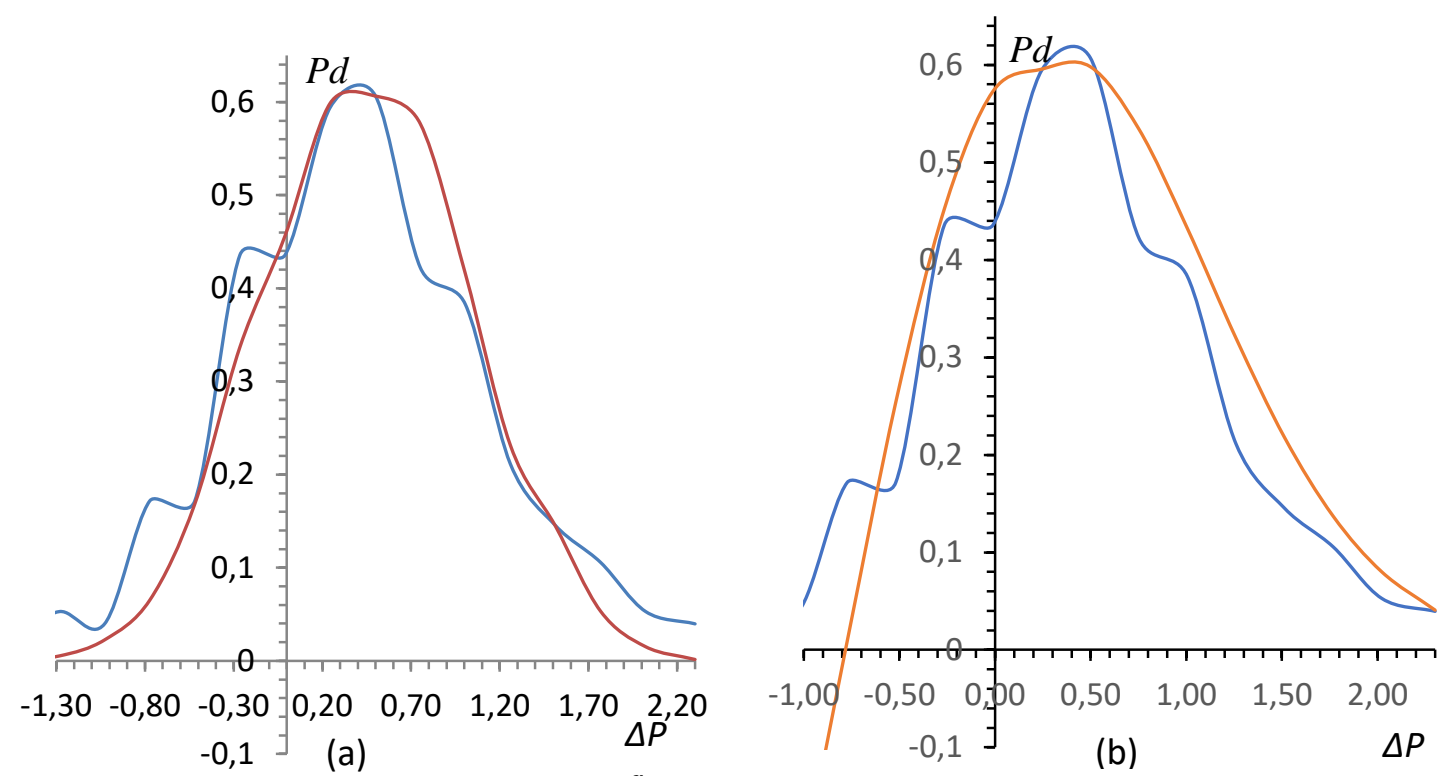

Figure 6: Approximation of the random rest of maxima (blue line) by (a) Gaussian distribution; (b) Maxwell distribution (red line)

For the Gaussian distribution, $F_{1}(x)=\beta \frac{1}{\sigma \sqrt{2 \pi}} \exp \left[-\frac{(x-\alpha)^{2}}{2 \sigma^{2}}\right]$ the optimal parameters are $\alpha=0.277, \sigma=0.5, \beta=0.78$. In this case, the approximation occurs uniformly over the entire region, but not very well in the region of low probabilities ("tails" of the distribution). The Maxwell distribution $F_{2}(x)=\frac{(x-\alpha)}{\sigma^{2}} \exp \left[-\frac{(x-\alpha)^{2}}{2 \sigma^{2}}\right]$ with the parameters $\alpha=1, \sigma=0.8$ approximates the "tails" much better, but poorly approximates the region of small negative pressure values.

A similar study was carried out for the pressure minima. The behavior of climatic seasonal minima is shown in Figure 7 (year to year averaged over the observational data set).

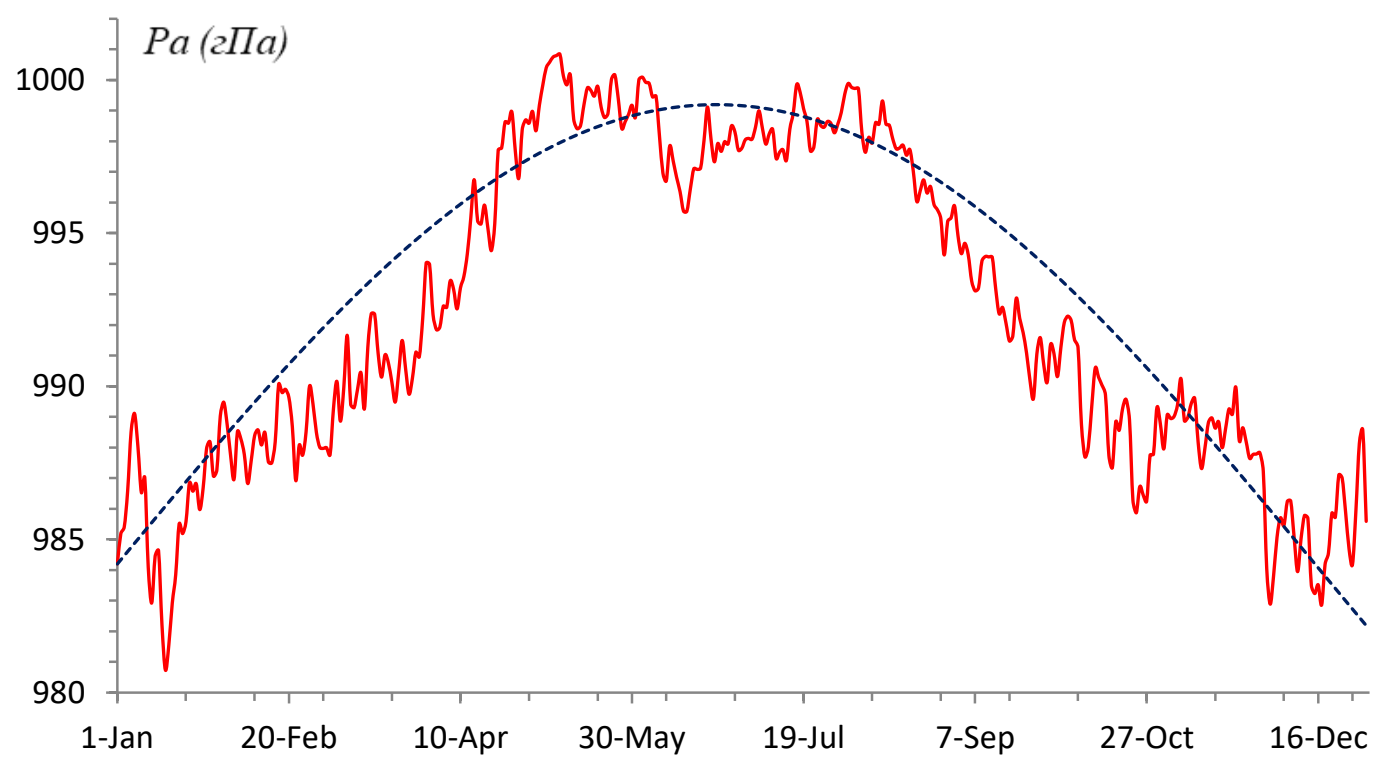

Figure 7: Curve of averaged year to year minima (red line) and its approximation line (blue dashed line) 


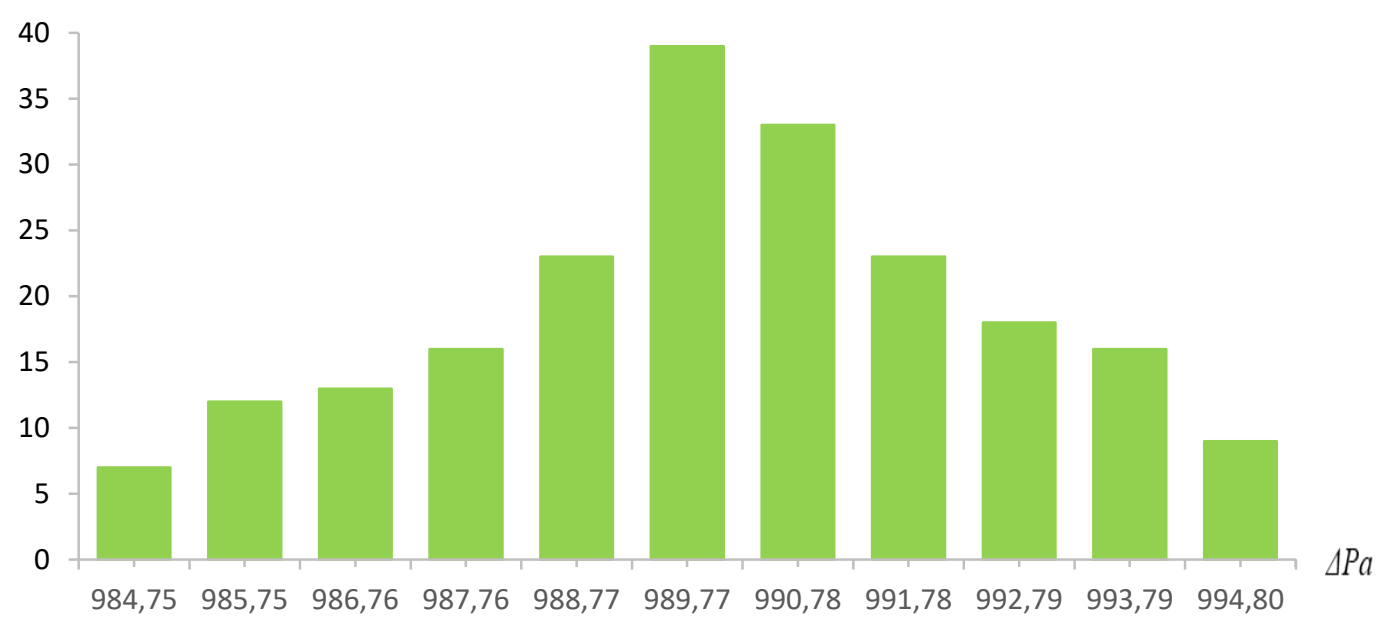

Figure 8: Hystogram of averaged annual cycle

The curve of averaged minima (1948-2008 yr over entire region) and its approximation $f_{i}=A+B \sin \omega x_{i}, A=984,2, B=15, \omega=0,01\left(x_{i}=0,9 * k, k=0,1, \ldots, 368\right)$ presented in Figure 7 . The histogram is shown in Figure 8.

According to an applied method the corresponding probability function is approximated by Maxwell distribution $F_{2}(x)=\frac{(x-\alpha)}{\sigma^{2}} \exp \left[-\frac{(x-\alpha)^{2}}{2 \sigma^{2}}\right]$, where $\alpha=0, \sigma=1$ (Figure 9).

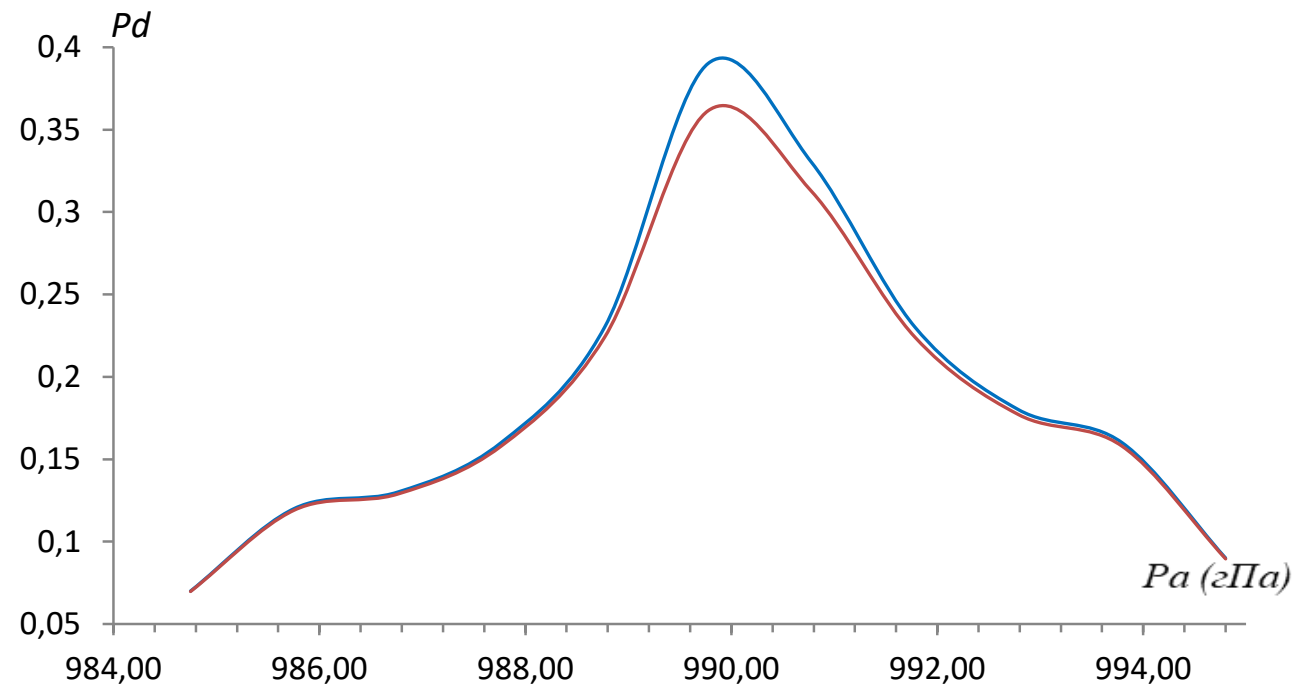

Figure 9: Approximation of the rest of minima by Maxwell distibution (red line shows an the approximation and blue line shows the origin function)

From this figure (Figure 9) it can be seen that the Maxwell distribution with the above parameters constructed by the method of maximum likelihood and tested by the $\chi^{2}$ criterion with 12 degrees of freedom (the division of the pressure interval into 14 subintervals and 2 parameters was estimated by sample) agrees very well with observations (with a confidence level of 95\%). It can be noted that for the minima the model of the sum of the fixed trigonometric functions plus the random remainder is in better agreement with the observations than for the maxima. This can be explained by the fact that for the polar zone of Russia cyclones, their physical features are more characteristic than anticyclones and their variability. 


\section{The upper boundaries determination for the pressure fields}

Analyzing the variability of the pressure field, we used its representation in the form of a stochastic differential equation, namely

$$
d X=a(t, X) d t+b(t, X) d W .
$$

In (1) it is denoted $d X=X(t+d t)-X(t)$. That is the variability of the pressure at the fixed spatial point, $a(t, X), b(t, X)$ are coefficients of drift and diffusion, respectively. They defined by (2) according to [12]

$$
\begin{aligned}
& a(t, x)=(d t)^{-1} \int_{-\infty}^{\infty}(y-x) d P(y / x) ; \\
& b^{2}(t, x)=(d t)^{-1} \int_{-\infty}^{\infty}(y-x)^{2} d P(y / x)-d t a^{2}(t, x),
\end{aligned}
$$

where $P(y / x)$ is a conditional probability of the transition of the process $X(t)$ from state $x$ into state $y$, that is $P(y / x)=P(X(t+d t)=y / X(t)=x), d W$ stands for the standard notation of the Gaussian "white noise" with zero mean and uniquely variation. The calculation methods of those variables are defined in $[17,18]$.

Form, the expression (1) will be written as $X(t)=X(0)+\int_{0}^{t} a(\tau, x(\tau)) d \tau+\int_{0}^{t} b(\tau, x(\tau)) d_{\tau} W$. Then breaking down the entire interval $[0, t]$ into subintervals $\Delta \tau=\tau_{i+1}-\tau_{i}$, and then, replacing the integral by integral sum we yield,

$$
\int_{0}^{t} b(\tau, x(\tau)) d_{\tau} W \cong S(t)=\sum_{u=0}^{m} b\left(\tau_{i}\right)\left(W\left(\tau_{i+1}\right)-W\left(\tau_{i}\right)\right) .
$$

From (3) one can see that we deal with the sum of independent random variables with zero mean and variance equaled $B=\sum_{i=0}^{m} b^{2}\left(\tau_{i}\right) \Delta \tau$. That means, the variance $B=\sum_{i=0}^{m} b^{2}\left(\tau_{i}\right) \Delta \tau>n \Delta \tau \sigma_{\min }^{2}$ approximately equaled, $B \sim t C$, where $C$ is some positive. From the latter representation and also from the assumption that the pressure values are bounded the statement of the Petrov's theorem [19] follows and the equality (4) holds

$$
\lim \frac{S(t)}{\sqrt{B(t) \ln \ln B(t)}}=1(\text { almostsure }) .
$$

This gives to assess the upper boundaries for the process $X(t)$, as follows

$$
|X(t)| \leq|X(0)|+\left|\int_{0}^{t} a(\tau, x(\tau)) d \tau\right|+\sqrt{2 B \ln \ln B}
$$

(with the probability 1 ) when $t \rightarrow \infty$.

In Figures 10 and 11 one can see that the coefficient $b^{2}(t, x)$ quite well corresponds to the coefficient $a(t, x)$, with some differences. So, from Figure 10 that the seasonal variation for the coefficient $b^{2}(t, x)$ is less pronounced, for example, it is almost invisible in April or July, and the interannual variation reflects the 11-year cycle worse (although it also exists) and the quasi-biannual cycle is better than the coefficient $a(t, x)$. Neither coefficient $a(t, x)$ nor $b^{2}(t, x)$ contain any linear trends. 


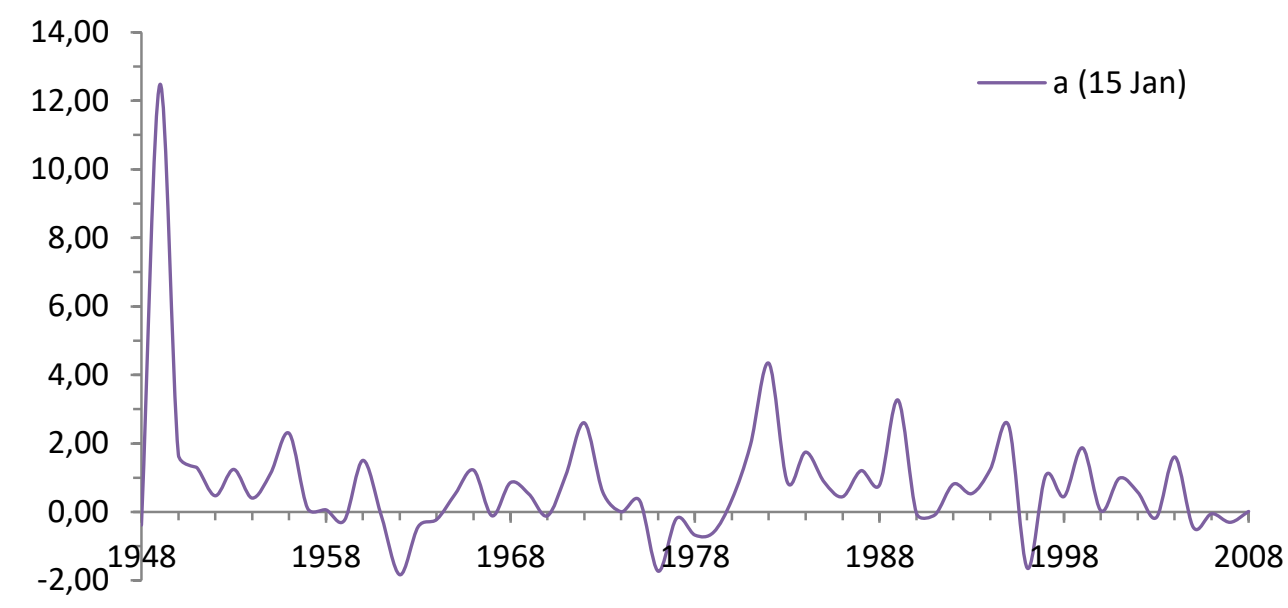

Figure 10: Graph for coefficient $a(t, x)$ from 1948 until 2008 years (measured at 0 o'clock Jan 15)

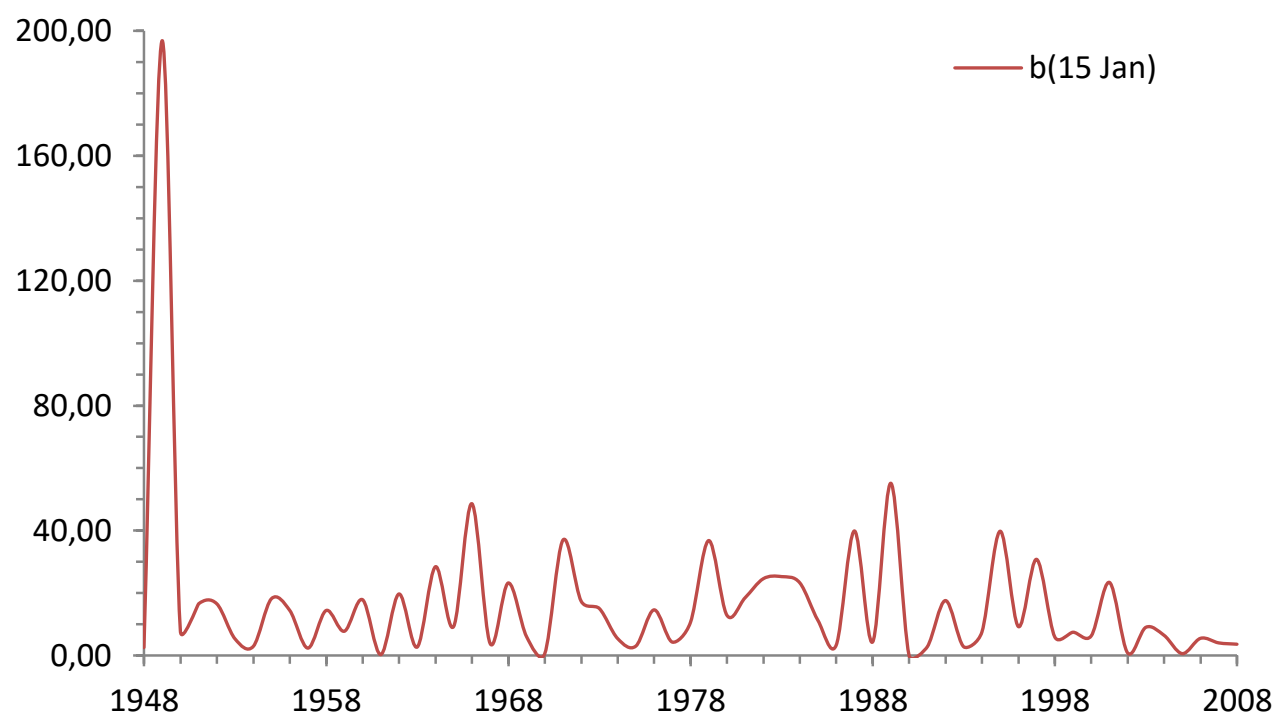

Figure 11: Graph for coefficient $b^{2}(t, x)$ from 1948 until 2008 years (measured at 0 o'clock Jan 15)

\section{Conclusions}

The paper proposes and implements methods of probabilistic analysis of the time series of atmospheric pressure over 60 years. It is shown that the climatic seasonal variability constructed according to such a series and the maximum and minimum are well approximated by the sum of the regular and stochastic terms. At the same time, a quantitative assessment of the deviation of the real pressure from the seasonal variation in the form of the probability density distribution is given. It is shown that the deviation is asymmetric, which is an unobvious research result. For the maximum and minimum, the best approximations were constructed, and these approximations were tested by known methods of statistical analysis, including the maximum likelihood method, the least squares method and methods (tests) of goodness, in particular, the $\chi^{2}$ test.

Such a study has both a purely physical application, that is, it allows explaining the nature, genesis and distribution of large-scale atmospheric formations in a climatic year, and a prognostic one, that is, it allows to understand and track trends in the climate, and also quantify the scale and variability of large-scale atmospheric processes. 


\section{Acknowledgements}

The work was carried out within the framework of the themes of the Ministry of Education and Science of the Russian Federation 0128-2021-0002 IO RAS and "Mathematical Methods for Data Analysis and Forecasting" of the Federal Research Center of CSC RAS.

\section{References}

[1] M. Kendall, A. Stuart, J. K. Ord, The Advanced Theory of Statistics. Volume 3: Design and Analysis, and Time-Series. Fourth edition Hardcover, 1983.

[2] J. Murphy, Technical analysis of the futures markets. A Comprehensive Guide to Trading Methods and Applications. New York Institute of Finance, 1986.

[3] V. E. Prival'skij, Statisticheskaya predskazuemost' srednej godovoj temperatury vozduha severnogo polushariya, Dokl. AN SSSR 257, 6 (1981) 1342-1345.

[4] I. I. Zveryaev, I. M. Yashayaev, Sezonnaya izmenchivost' polej davleniya, temperatury vody i vozduha v Severnoj Atlantike po dannym COADS, Izvestiya AN SSSR. Fizika atmosfery i okeana 2 (1996) 222-239.

[5] I. E. Frolov, Z. M. Gudkovich, V. P. Karklin, E. G. Kovalev, V. M. Smolyanickij, Klimaticheskie izmeneniya ledovyh uslovij v arkticheskih moryah evrazijskogo shel'fa, Problemy Arktiki i Antarktiki 75 (2007) 149-160.

[6] I. Frolov, Z. Gudkovich, V. Karklin, E. Kovalev, V. Smolyanitsky, Climate Change in Eurasian Arctic Shelf Seas. Centennial Ice Cover Observations: Praxis Publishing Ltd, Chichester, UK, 2009.

[7] F. Fetterer, V. F. Radionov (eds), Environmental Working Group Arctic Meteorology and Climate Atlas, Version 1. NSIDC, Colorado, USA. 2000. https://doi.org/10.7265/N5MS3QNJ.

[8] Y. Zhao, A. K. Liu, Arctic sea-ice motion and its relation to pressure field. J. Oceanography 63, 505-515 (2007). https://doi.org/10.1007/s10872-007-0045-2.

[9] R. Przybylak, P. Wyszyński, Z. Vízi, J. Jankowska, Atmospheric pressure changes in the Arctic from 1801 to 1920, The International Journal of Climatology 33 (2013) 1730-1760. https://doi.org/10.1002/joc.3546.

[10] Longterm Changes In Atmospheric Pressure Fields And Atmospheric Circulation Indices URL: https://www.climate-policy-watcher.org/arctic-seas/longterm-changes-in-atmospheric-pressurefields-and-atmospheric-circulation-indices.html.

[11] O. Humlum, Climate 4you. 2012. URL: http://www.climate4you.com/index.htm.

[12] E. G. Kovalev, A. V. Yulin, Automated prognostic system for scientific-operational support of navigation in the Arctic. AARI Proc. 438 (1998) 73-82.

[13] Z. M. Gudkovich, Ye. G. Kovalev, Conformity of large-scale processes in the atmosphere, ocean and ice cover of the northern polar area. AARI Proc. 437 (1997) 17-29.

[14] K. Belyaev, G. Mikhaylov, A. Salnikov, N. Tuchkova, Seasonal and Decadal Variability of Atmosphere Pressure in Arctic, its Statistical and Temporal Analysis, CEUR Workshop Proceedings 2784 (2020) 51-61. URL:http://ceur-ws.org/Vol-2784/rpaper05.pdf.

[15] K. Belyaev, G. Mikhaylov, A. Salnikov, N. Tuchkova, Sezonnaya i mnogoletnyaya izmenchivost' atmosfernogo davleniya v Arktike, statisticheskij i vremennoj analiz, Russian Digital Libraries Journal. 2021. V. 24. No. 1. S. 57-73. https://doi.org/10.26907/1562-5419-2021-24-1-57-73.

[16] S. K. Popov, Influence of sea ice on the harmonic tidal oscillations of sea level and currents in the Barents and White seas, Trudy Gidrometcentra RF, Gidrometeorologicheskie issledovaniya i prognozy 4, 370 (2018) 137-155.

[17] B. A. Birman, T. V. Berezhnaya, A. D. Golubev, Osnovnye pogodno-klimaticheskie osobennosti, nablyudavshiesya na Severnom polusharii Zemli v 2017 g. Analiticheskij obzor. FGBU 'Gidrometcentr Rossii', Moscow. 2017.

URL:http://www.meteorf.ru/upload/iblock/dc0/Бирман\%20Климат_2017.pdf.

[18] I. Gihman, A. Skorohod, Vvedenie v teoriyu sluchajnyh processov. Nauka, Moscow, 1965.

[19] V. V. Petrov, O zakone povtornogo logarifma, UMN 15, 2 (1960) 189-194. 